\title{
BARRADOS: UM ENSAIO SOBRE OS BRASILEIROS INADMITIDOS NA EUROPA E O CONTO DA ALDEIA GLOBAL
}

\author{
Patrícia Duarte Rangel \\ Brasília (DF), Editorial Abaré, 2012, 160 p. \\ Barrados.pdf IN: http://www.barrados.org.br
}

A publicação desse pequeno livro de Patrícia Rangel, trazendo à luz para um público mais amplo o desenvolvimento de sua dissertação de mestrado, vale acima de tudo pelo exercício de reflexão sobre uma experiência que normalmente fica nas sombras, vivida nos porões das relações atuais entre os Estados-Nação. Ela viveu o trauma de ser detida injustificadamente no Aeroporto de Barrajas em Madri, Espanha, em março de 2008, quando fazia uma conexão normal na sua viagem para participar de um Congresso de Antropologia em Portugal. Não fosse sua condição de estudante de classe média, o fato de ser aguardada num Congresso Internacional, com todos os requisitos para entrada na Europa preenchidos, talvez o seu caso passasse despercebido, como o de tantos outros imigrantes do assim dito Terceiro Mundo, rechaçados pela União Europeia. No entanto, a sua detenção chegou ao conhecimento da imprensa brasileira, devido ao inusitado do acontecimento, e sua divulgação ganhou grande repercussão, criando um constrangimento diplomático entre Brasil e Espanha. A autora não foi, em nenhum momento, alguém que se conformasse com essa situação, opondo seu olhar de estudante de ciências sociais e sua já adquirida bagagem de turista internacional como instância crítica da realidade que vivenciou. Trata-se, portanto, de um testemunho precioso, publicado para ser conhecido sem qualquer restrição. Por isso ele está amplamente difundido na internet para ser baixado livremente, sendo que sua edição em papel ficou reduzida a apenas cem cópias.

A reflexão sobre essa experiência, denominado por ela "um sequestro legitimado pelas regras da União Europeia" (p. 11), é o tema desse trabalho, que não busca um maior rigor científico, se limitando ao que seria um 
estudo etnográfico, ou uma "conversação interior" (p. 13). O propósito da autora seria de: "com base em fragmentos de lembranças de minha experiência, montar um compêndio de reflexões, de forma a transcender minha vivência e relacioná-la a um problema estrutural que demanda soluções coletivas (...) Minha intenção não é de explicar os acontecimentos vivenciados, mas sim explicitar e problematizar o que observei". É com essa intenção que ela vai introduzindo, um tanto aleatoriamente, vários autores, como Bauman, Hall, Kant, Foucault, Negri, entre outros, na medida em que eles sugerem pistas para o entendimento das situações por que passou. Sua escrita descreve, assim, livre de qualquer grande preocupação teórica ou conceitual, aquilo que foi vivido. É um livro feito para despertar interrogações e questionamentos. Ele busca sugerir inúmeras intuições novas de estudo dessa condição vivida atualmente pelos migrantes, mais do que articular análises bem elaboradas que ajudem no seu entendimento. Aí se encontra sua originalidade e grande riqueza.

O livro se divide em seis partes que, na medida em que avançam no relato de sua experiência, vão apresentando os diferentes níveis da problemática vivenciada. Em cada capítulo, numa narrativa solta, descrevem-se as situações pelas quais a autora passou, descrevendo os sentimentos e impressões vividos nas relações com as diferentes figuras com que se defronta no Aeroporto de Barrajas. Para refletir sobre esse "universo paralelo do Aeroporto" que aos poucos vai descortinando, e apresentar seus temas de debate, introduz as iluminações trazidas pelos autores citados. Uma técnica interessante que utiliza, tanto para segurar a atenção do leitor, como para sugerir de maneira mordaz o que as situações lhe sugerem, está no uso de intertítulos, às vezes longos, a cada duas ou três páginas, tais como: "fomos maltratados porque era natural que fôssemos", "a identidade pode mudar de acordo com a ocasião", "Kant morreu há dois séculos", "de como já éramos todos, detidos e policiais, oprimidos e disciplinados, bem antes de cruzarmos a porta da prisão em Madri", "quando a experiência do sofrimento não é apenas de uma pessoa, e sim um problema coletivo". São como marcos que assinalam simultaneamente os paradoxos experimentados pela autora e um instigante convite para uma investigação sobre o que existe por trás de cada uma das situações.

O primeiro capítulo, "Quem é gente pra gente?", reflete sobre o que sustenta o reconhecimento social entre pessoas diferentes, isto é, o que faz com que as pessoas sejam vistas como "um de nós" ou simplesmente como o "outro". Desse reconhecimento dependeriam os sentimentos de respeito e estima, ou de preconceito e exclusão. Nele também se 
apoiariam a vivência dos valores da cidadania. A autora, que vivenciou anteriormente a condição de turista em Londres, por ocasião de um projeto de intercâmbio, tendo viajado então por vários países da Europa, faz uma comparação com essa experiência de ser barrada no Aeroporto. Introduz a distinção prática, velada, entre os "turistas" (dos países do chamado Primeiro Mundo) e os "semi-turistas" (da América Latina, África, ou todos aqueles que vêm do dito Terceiro Mundo), ou explicita, entre os "turistas" e os "vagabundos", um julgamento de valor dicotômico para enquadrar as diferentes pessoas que circulam pelo ambiente europeu.

O segundo capítulo, "Liberdade pra quem e até onde?", relata sua chegada a Barrajas, e a sequência de acontecimentos que a levaram a um encarceramento não declarado, numa situação em que ficou submetida ao arbítrio dos policiais de plantão. É a oportunidade para lançar suas reflexões sobre o exercício da liberdade de qualquer pessoa poder circular pelas nações, referindo-se ao pensamento expresso na "Paz Perpétua" de Kant. É também motivo para questionar os contrastes da realidade atual e seus paradoxos em torno da liberdade de ir e vir, quando se trata da circulação de qualquer pessoa entre as democracias atuais. Procura levantar os significados e as condições, explícitos e implícitos, quanto à entrada numa comunidade estrangeira, e as práticas arbitrárias de rechaço de migrantes.

O terceiro capítulo, "Cadernos de Cárcere", talvez seja o mais interessante, por trazer uma descrição minuciosa das condições de detenção pelas quais a autora passou, como também as impressões que ela reteve de suas relações com os funcionários do Aeroporto, os policiais, os outros estrangeiros que se encontravam nas mesmas condições. Interessante, sobretudo, pelas temáticas que ela levanta quando se trata da criminalização do migrante, e como ele se vê reduzido a "coisa", na "terra de ninguém" em que se convertem os espaços internos do Aeroporto. Nesse mundo kafkiano, visto como uma situação fugaz de "campo de concentração", impera a burocracia policial, a lógica cotidiana (ou a falta de lógica) do humor arbitrário dos pequenos funcionários, que humilham e abusam de seu "micro-poder". A autora se serve de referências de Michel Foucault, para levantar os traços do que seria uma "instituição total", com sua lógica própria de "encarceramento", disciplinando discricionariamente o cotidiano, num controle do espaço que guarda a forma de um "panóptico". Ao final, à semelhança de outros detidos, se viu obrigada a assinar uma declaração em que acatava a falsa acusação que lhe era feita, ou uma "profecia autorrealizável": "uma afirmação inicialmente falsa que leva a 
determinadas condutas que acabam por torná-la verdadeira" (p. 72). A esse propósito, a descrição do interrogatório final, com seus simulacros de "advogado fantoche" e "tradutora de portunhol", foi o melhor retrato do desrespeito dissimulado dos direitos das pessoas detidas. Em síntese, trata-se da descrição de um "não-lugar", isento de qualquer referência à cidadania ou aos direitos fundamentais da pessoa humana, pois aqueles que aí estão submetidos estão à margem de qualquer legalidade (pois se encontram num espaço de "limbo" até do próprio direito internacional), não podendo recorrer a ninguém.

No quarto capítulo, "Que soberania?", a autora se debruça sobre o que uma situação como essa faz pensar a propósito da autoproclamada soberania do Estado. Ela parte do discurso de um dos policiais que vigiavam as pessoas detidas, que teria aproveitado a ocasião para discorrer frente àquelas que estavam para serem deportadas, utilizando-se do seu senso comum de agente de segurança do Estado, sobre a legitimidade da ação policial no controle de todos os estrangeiros que tentam entrar de maneira irregular no país. Também se serve dos infelizes pronunciamentos do embaixador da Espanha no Brasil, à época dos acontecimentos, ao procurar justificar o injustificado da situação vivida pela autora. É a oportunidade para estudar os anacronismos e anomalias da concepção de soberania que na prática são mobilizadas para resguardar as fronteiras da União Europeia, como também para enquadrar a identidade nacional, utilizando-se de conceitos como Estado, território e nação.

O quinto capítulo, "O Espetáculo", retoma os enfoques dados pela imprensa brasileira ao seu caso, da denúncia aos efeitos de espetacularização que se seguiram, perguntando-se "em que medida a transmutação de uma notícia de uma denúncia em uma notícia pitoresca não reforça preconceitos e estereótipos" (p. 99). Aqui percebe claramente como ela, estudante branca de classe média, distingue-se dos milhares de migrantes que são cotidianamente barrados nos Aeroportos dos países mais poderosos do mundo, e que são continuamente ignorados. $\mathrm{Na}$ verdade, a imprensa, ao "pescar" seu caso pitoresco, e transformá-lo em espetáculo para os indignados expectadores brasileiros, acaba colocando na sombra o drama de milhares desconhecidos. De um lado, a autora se revela consciente dessa ambiguidade da imprensa, que noticia um fato e cria um personagem, para ao mesmo tempo excluir e estigmatizar indiretamente outros tantos fatos e pessoas. Contudo, por outro lado, acaba se traindo, ao mostrar involuntariamente seu olhar de classe, quando chama os migrantes de "multidão de sujeitos sem rosto, sem 
história e sem individualidade" (p. 102). Na contraposição entre "turistas" e "vagabundos", ela não chega a perceber que não é porque os migrantes são estigmatizados como "vagabundos", que eles seriam "sem rosto, sem história e sem individualidade". A grande tarefa é justamente trazer à luz e valorizar o verdadeiro rosto, individualidade e história de todo migrante.

O sexto capítulo, "Jihad VS. McWorld", parece se colocar como a conclusão de seu trabalho. Também parece ser o capítulo mais fraco, seja porque não traz mais o conteúdo do relato de sua experiência em Barrajas, seja porque a autora sente a necessidade de discorrer sobre as questões políticas referentes à migração. Ela se vê obrigada a articular ideias, com fundamentação teórica frágil e pouco articulada, não lhe permitindo ir além do senso comum. Uma de suas fragilidades mais evidentes é considerar ingenuamente que os posicionamentos diplomáticos do Brasil e de outros países da América Latina são mais atualizados que os da União Europeia, apenas porque eles se contrapõem a medidas como a Diretiva de Retorno. Toda elogios ao posicionamento do Brasil, ela não chega a considerar outras motivações próprias da razão de Estado que estariam atuando nesse campo de disputa internacional. Sem entrar no mérito de suas ideias sobre a defesa da cidadania e dos direitos de todos os migrantes, as quais também partilhamos, seria de perguntar: por que não chegou a utilizar, e nem mesmo mencionar, a abundante bibliografia que trata com mais propriedade das questões políticas relativas à migração?

No entanto, essas lacunas não desabonam a iniciativa dessa publicação e sua proposta de refletir em primeira mão sobre uma experiência atualmente vivenciada de maneira dolorosa por tantos migrantes. $\mathrm{O}$ fato de uma estudante em ciências sociais se debruçar sobre os temas que ela suscita, servindo-se de suas impressões pessoais, dá um corpo novo às temáticas levantadas. A argúcia e indignação que percorrem sua narrativa ajudam a tornar sua reflexão mais candente, apesar de suas insuficiências teóricas. A dedicatória ao Embaixador da Espanha no Brasil à época é apenas um detalhe sutil, revelador da ironia afiada da autora. Todo material, enfim, com vários trechos das notícias publicadas, fotos, comentários, tornam o livro particularmente agradável de ser lido, e sua disponibilização via internet é um verdadeiro serviço à causa dos migrantes.

Sidnei Marco Dornelas

Comissão Episcopal para a Missão Continental e Setor Pastoral da Mobilidade Humana - CNBB. 
